Check for updates

Cite this: RSC Adv., 2017, 7, 54063

Received 17th October 2017

Accepted 16th November 2017

DOI: $10.1039 / c 7 r a 11462 a$

rsc.li/rsc-advances

\title{
On the solvation of metal ions in liquid ammonia: a molecular simulation study of $\mathrm{M}\left(\mathrm{NH}_{2}\right)_{x}\left(\mathrm{NH}_{3}\right)_{y}$ complexes as a function of $\mathrm{pH}$
}

\begin{abstract}
Dirk Zahn (D)*
The solvation of mono-, di- and trivalent metal ions in liquid ammonia is characterized from molecular simulations. A central focus of the analyses is given by metal ion acidity within the respective solvent complexes. For this purpose, a recently developed model for estimating the $\mathrm{p} K$ of the auto-protolysis reaction $2 \mathrm{NH}_{3} \rightarrow \mathrm{NH}_{4}{ }^{+}+\mathrm{NH}_{2}{ }^{-}$is transferred to assessing the 'local' $\mathrm{pK}$ of ammonia molecules coordinating a metal ion. On this basis, we identify $\mathrm{M}^{1 / 11}\left(\mathrm{NH}_{3}\right)_{n}{ }^{+/++}$complexes $\left(\mathrm{M}=\mathrm{Na}^{+}, \mathrm{K}^{+}, \mathrm{Mg}^{2+}\right.$ with $n=6$ and $\mathrm{M}=\mathrm{Ca}^{2+}$ with $n=8$, respectively) as predominant species unless extremely ammono-basic conditions are imposed. On the other hand, the trivalent $\mathrm{Al}^{3+}$ and $\mathrm{Ga}^{3+}$ species were found to favor $\left[\mathrm{Al}\left(\mathrm{NH}_{2}\right)_{3}\left(\mathrm{NH}_{3}\right)_{2}\right]^{0}$ and $\left[\mathrm{Ga}\left(\mathrm{NH}_{2}\right)_{4}\right]^{-}$complexes, respectively. The negatively charged complexes dominate over a wide range of $\mathrm{pH}$ for gallium ion solvation in ammonia, whilst $\left[\mathrm{Al}\left(\mathrm{NH}_{2}\right)_{4}\left(\mathrm{NH}_{3}\right)_{2}\right]^{-}$complexes require moderately ammono-basic solutions.
\end{abstract}

\section{Introduction}

While metal ion solvation in water has been investigated extensively, ${ }^{1}$ much less information is available for less common solvents. This situation hampers the fundamental understanding of solvothermal syntheses other than those based on water. Indeed, the hydrothermal syntheses of oxides experienced almost 200 years of development and is by now well-established in industry and their production exceeds megatons per year (mainly of $\mathrm{Al}_{2} \mathrm{O}_{3}$ ). ${ }^{2,3}$ However, solvothermal syntheses based on ammonia are currently becoming increasingly popular as potential routes to nitrides and amides., ${ }^{\mathbf{4} 5}$

Ammonothermal syntheses appear particularly interesting for aluminum and gallium nitrides which are semiconductors that are difficult to formulate as large single crystals. ${ }^{\mathbf{4 , 6}, 7}$ It is thus of fundamental importance to characterize the nature of $\mathrm{Al}^{3+}$ and $\mathrm{Ga}^{3+}$ ions in ammonia solution. However, also the role of di- and monovalent metal ions is of eminent interest as these species are used for mixed metal nitrides/amides. ${ }^{4}$ The larger the valence of the metal ion the more imperative it becomes to consider its effect on possible proton transfer reactions. In analogy to water, liquid ammonia also reflects a protic solvent with a $\mathrm{pK}$ of 32 (at $1 \mathrm{~atm}$ and $239 \mathrm{~K}$ ) and 28 (at $300 \mathrm{~K}$ with fixed density to that at $239 \mathrm{~K}$ ), respectively. ${ }^{8}$ Such low tendencies to solvent autoprotolysis may however change drastically for molecule coordinating a metal ion.

Lehrstuhl für Theoretische Chemie, Computer Chemie Centrum, Friedrich-Alexander Universität Erlangen-Nürnberg, Nägelsbachstraße 25, 91052 Erlangen, Germany. E-mail:dirk.zahn@fau.de
While hard to assess from experiment - in particular when high-pressure autoclaves are used - molecular dynamics simulations provide particularly detailed insights into atomic scale interactions accounting for ion solvation. In the present study, we use this technique to explore metal ion solvation in ammonia in combination with a recent approach to estimating the $\mathrm{p} K$ for the autoprotolysis of solvent molecules in bulk ammonia. $^{8}$

\section{Theory}

By means of Boltzmann statistics, the equilibrium constants of auto-protolyses processes may be related to the underlying free energy change $\Delta G$. Within a recently developed quantum/ molecular mechanics approach this is calculated from the quantum chemical assessment of the difference in proton affinity of the molecules in the gas phase and the change in solvation free energy as estimated from molecular dynamics simulations. ${ }^{8}$ When moving from auto-protolysis in the bulk liquid to the deprotonation of ammonia molecules within metal ion complexes, we can estimate free energy differences analogously. Thus, the $\mathrm{p} K$ of the bulk liquid changes to a 'local $\mathrm{p} K$ ' according to Scheme 1.

Where $M$ refers to a metal ion and $q$ to the charge of $\left[\mathrm{M}\left(\mathrm{NH}_{2}\right)_{x}\left(\mathrm{NH}_{3}\right)_{y}\right]^{q}$ complexes. Note that $K$ and $\mathrm{p} K$ refer to the overall reaction involving two $\mathrm{NH}_{3}$ molecules (one donor and one acceptor) and are thus dimensionless. Upon deprotonation of $\left[\mathrm{M}\left(\mathrm{NH}_{2}\right)_{x}\left(\mathrm{NH}_{3}\right)_{y}\right]^{q}$ complexes, the $\mathrm{NH}_{4}{ }^{+}$ion is always migrated to the solution. The resulting $\left[\mathrm{M}\left(\mathrm{NH}_{2}\right)_{x+1}\left(\mathrm{NH}_{3}\right)_{y+z-2}\right]^{q}$ complex may change its overall coordination number by associating $(z>0)$ or dissociating $(z<0)$ ammonia molecules to/from its 


\begin{tabular}{|c|c|}
\hline $\mathrm{NH}_{3}+\mathrm{NH}_{3} \rightleftharpoons \mathrm{NH}_{2}^{-}+\mathrm{NH}_{4}^{+}$ & $\Rightarrow\left[\begin{array}{l}{\left[\mathrm{M}\left(\mathrm{NH}_{2}\right)_{x}\left(\mathrm{NH}_{3}\right)_{y}\right]^{q}+z \mathrm{NH}_{3} \rightleftharpoons} \\
{\left[\mathrm{M}\left(\mathrm{NH}_{2}\right)_{x+1}\left(\mathrm{NH}_{3}\right)_{y+z-2}\right]^{q-1}+\mathrm{NH}_{4}^{+}}\end{array}\right.$ \\
\hline$K=\frac{K_{\mathrm{A}}}{c\left(\mathrm{NH}_{3}\right)}=\frac{c\left(\mathrm{NH}_{4}^{+}\right) c\left(\mathrm{NH}_{2}^{-}\right)}{c\left(\mathrm{NH}_{3}\right)^{2}}=\exp \left[-\frac{\Delta G}{k_{\mathrm{B}} T}\right]$ & $K=\frac{c\left(\mathrm{NH}_{4}^{+}\right) c(\mathrm{M}(x+1))}{c(\mathrm{M}(x)) c\left(\mathrm{NH}_{3}\right)^{2}}=\exp \left[-\frac{\Delta G+\Delta \Delta G}{k_{\mathrm{B}} T}\right]$ \\
\hline $\mathrm{p} K_{\mathrm{A}}($ bulk liquid $)=-\log _{10}\left[c\left(\mathrm{NH}_{3}\right) \cdot 11 \mathrm{~mol}^{-1}\right]+\log _{10}[\mathrm{e}] \frac{\Delta G}{k_{\mathrm{B}} T}$ & $\mathrm{p} K=\mathrm{p} K_{\mathrm{A}}($ bulk liquid $)+\log _{10}\left[c\left(\mathrm{NH}_{3}\right) \cdot 11 \mathrm{~mol}^{-1}\right]+\log _{10}[\mathrm{e}] \cdot \frac{\Delta \Delta G}{k_{\mathrm{B}} T}$ \\
\hline
\end{tabular}

Scheme 1

coordination polyhedron. This depends on the specific metal ion as discussed in the results section.

Both sides of Scheme 1 refer to idealized systems, that is pure ammonia (left side of Scheme 1) and a single metal ion $M$ in pure ammonia (right side of Scheme 1), respectively. Note that activity coefficients used for interpreting experimental data of real solutions reflect the need to combine ammonia autoprotolyses in bulk $\mathrm{NH}_{3}$ and next to solvated ions. Using ideal solution models, our simulations however can address the respective equilibrium constants separately.

Within the metal complexes, the free energy change for autoprotolysis includes a correction term $\Delta \Delta G$, which represents the change in solvation free energy upon $\mathrm{NH}_{3} / \mathrm{NH}_{2}{ }^{-}$association to the metal ion. This specific change in local interactions is clearly dominated by the electrostatics and thus the potential energy of the underlying complexes in solution. To obtain inexpensive estimates of $\Delta \Delta G$ we therefore use the change in potential energy (averaged over time at $300 \mathrm{~K}$ ) of $\mathrm{NH}_{2}{ }^{-}$solvation in pure ammonia compared to association to the metal cluster.

\section{Simulation details}

The changes in solvation energy were assessed from molecular dynamics simulations based on molecular mechanics models. The force-fields for $\mathrm{NH}_{4}{ }^{+}, \mathrm{NH}_{3}$ and $\mathrm{NH}_{2}{ }^{-}$are adopted from our earlier work reported in ref. 8. For the mono- and di-valent metal ions we employed the Lennard-Jones model from Merz and coworkers. ${ }^{9,10}$ The $\mathrm{Al}^{3+}$ model could also be adopted from this group ${ }^{11}$ while for $\mathrm{Ga}^{3+}$ the force-field of Gale and coworkers was used..$^{12}$ This approach ensures formal charges for all ions, thus allowing to model complex formation/dissociation without the need of quantum mechanical calculations. The accuracy of the employed force-fields may be judged on the basis of the coordination numbers as observed from the experiment. While experimental data is still rather sparse, the coordination of alkali metal ions and of gallium ions as discussed in the results section provides a basis for such comparison.

In full analogy to our earlier study, ${ }^{8}$ the simulation system is based on a cubic box of 1000 ammonia molecules imposing periodic boundary conditions to mimic an infinite liquid phase. To this, one metal ion is inserted and $2-4$ ammonia are deprotonated (replaced by $\mathrm{NH}_{2}{ }^{-}$ions), depending on the valence of the metal ion. To also allow for possible overcompensation of the metal ion charge by amide association, we chose $\mathrm{Na}^{+} / \mathrm{K}^{+}+2 \mathrm{NH}_{2}^{-}+998 \mathrm{NH}_{3}, \mathrm{Mg}^{++} / \mathrm{Ca}^{++}+2 \mathrm{NH}_{2}{ }^{-}+$ $998 \mathrm{NH}_{3}$ and $\mathrm{Al}^{3+} / \mathrm{Ga}^{3+}+4 \mathrm{NH}_{2}{ }^{-}+996 \mathrm{NH}_{3}$ systems which excess charge was levelled using the homogeneous, diffuse background charge approach.

Molecular dynamics simulations were run by the dlpoly package using a time-step of $1 \mathrm{fs}$ and shifted-force cut-off potentials with $r_{\text {cut }}=12 \AA .{ }^{13}$ Each model was equilibrated for $1 \mathrm{~ns}$ at 240 $\mathrm{K}$ and $1 \mathrm{~atm}$ within constant temperature, constant pressure runs. To mimic an autoclave scenario, the volume is fixed to maintain the average solution density at $240 \mathrm{~K}$ whilst further molecular dynamics are performed at elevated temperature. Production runs

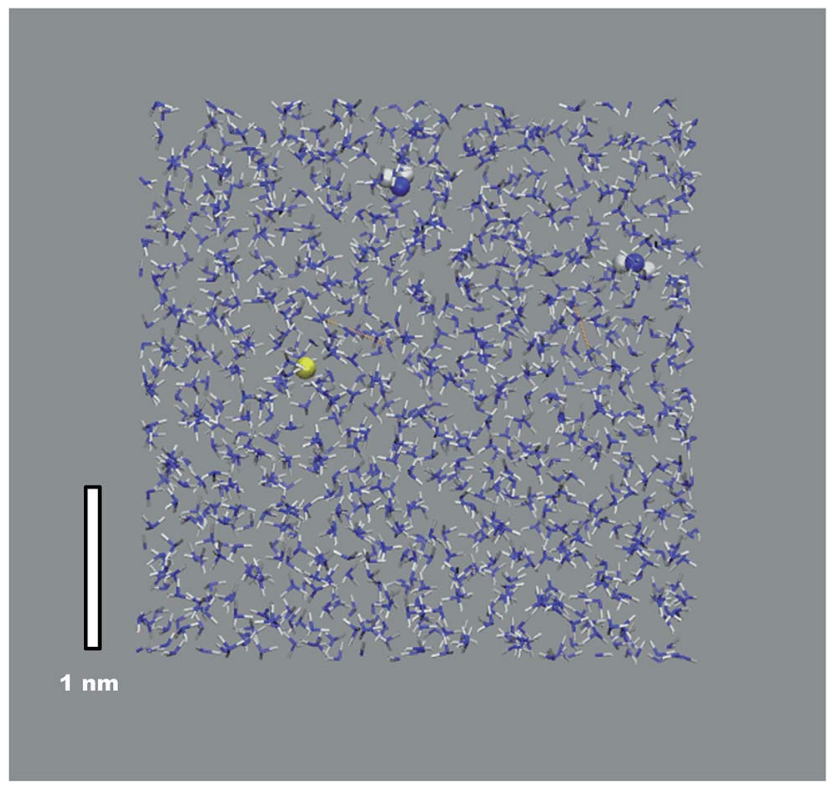

Fig. 1 Illustration of a cubic simulation cell as used for assessing metal ion (yellow, here $\mathrm{Mg}^{2+}$ ) solvation of in liquid ammonia ( $\mathrm{N}$ : blue, $\mathrm{H}$ : white). The snapshot shows $1 \mathrm{Mg}^{2+}$ and $2 \mathrm{NH}_{2}{ }^{-}$ions (highlighted in bold) dispersed in 998 molecules of $\mathrm{NH}_{3}$ at $300 \mathrm{~K}$. Mimicking an autoclave scenario, 3D periodic boundary are applied and the density is fixed to its average value at $240 \mathrm{~K}$ and $1 \mathrm{~atm}$. 
are performed for $0.5-1 \mathrm{~ns}$ at $300 \mathrm{~K}$ after allowing 100 ps relaxation. The quality of data sampling (i.e. the solvation energy differences) was monitored from comparing results obtained for the first half of the trajectory to that of the second part and imposing less than 1\% statistical error. Average nearest-neighbor distances and coordination numbers were computed by means of the corresponding radial distribution functions.

\section{Results}

An illustration of the overall simulation model is provide by the example of $\mathrm{Mg}^{2+}$ solvation in liquid ammonia in Fig. 1. This simulation run exhibited clearly separated ionic species, each coordinated by the $\mathrm{NH}_{3}$ solvent molecules only. This picture holds for all mono- and divalent metal ions investigated $\mathrm{Na}^{+}$, $\left.\mathrm{K}^{+}, \mathrm{Mg}^{2+}, \mathrm{Ca}^{2+}\right)$, however at different $\mathrm{M}\left(\mathrm{NH}_{3}\right)_{y}$ complex arrangements. While $\mathrm{Na}^{+}, \mathrm{K}^{+}$and $\mathrm{Mg}^{2+}$ ions are octahedrally coordinated, we found 8 -fold coordination to be preferred for the calcium ions (Fig. 2a). The corresponding metal-nitrogen atom distances are denoted in Tables 1 and 2. Note that the observed octahedral coordination for the alkali metal ions in pure ammonia nicely agrees with the experimentally identified coordination numbers with range from 5.5 to 6.4 for $\mathrm{Na}^{+}$and $\mathrm{Rb}^{+}$, respectively. ${ }^{\mathbf{1 4 , 1 5}}$

While this data is in line with earlier studies on mono- and divalent metal ion coordination by $\mathrm{NH}_{3},{ }^{16}$ the novel aspect of the present study is the assessment of amide formation assisted by the metal ion. For this purpose, $\mathrm{M}\left(\mathrm{NH}_{2}\right)_{x}$ clusters in ammonia solution were prepared and subjected to relaxation. For the mono- and divalent metal ions investigated, metal clusters with $x=0,1$ and 2 were found to be sufficiently metastable to assess time averages of the corresponding solvation energy. The energy difference for $\mathrm{NH}_{2}{ }^{-}$desolvation from liquid ammonia and association to the (solvated) metal cluster is then taken as the $\Delta \Delta G$ term in Scheme 1 for assessing the change in $\mathrm{p} K$ with respect to the bulk liquid. The 'local $\mathrm{p} K$ ' of ammonia within the $\mathrm{M}\left(\mathrm{NH}_{2}\right)_{x}$ clusters, along with the net free energy differences $\Delta G-\Delta \Delta G$ is provided in Tables 1-3.

For $\mathrm{Na}^{+}$and $\mathrm{K}^{+}$we find the predominant solvated species are octahedral $\mathrm{M}\left(\mathrm{NH}_{3}\right)_{6}{ }^{+}(\mathrm{M}=\mathrm{Na}, \mathrm{K})$ complexes unless extremely
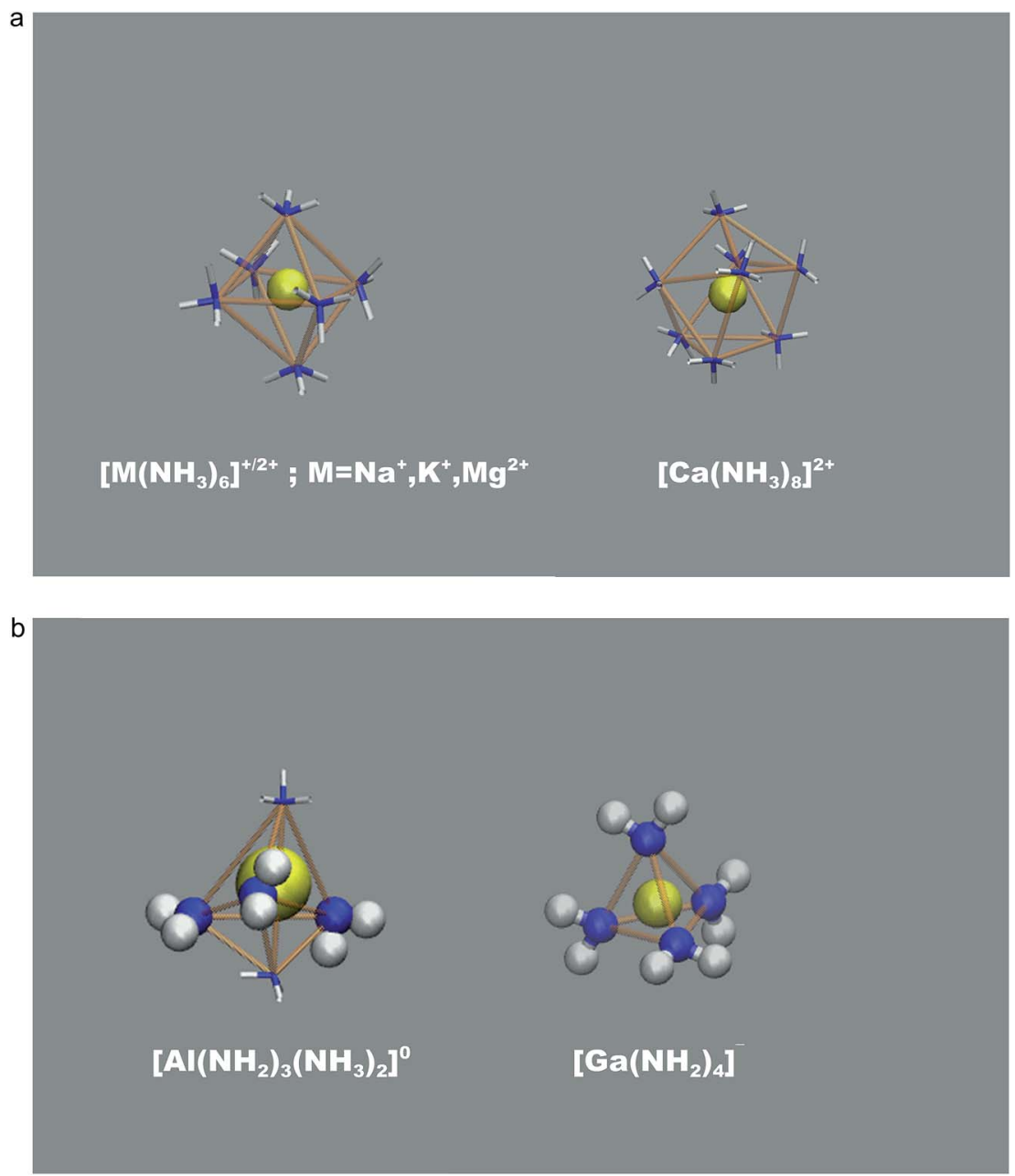

Fig. 2 (a). Mono- and divalent metal ion (yellow) solvation of in liquid ammonia ( $\mathrm{N}$ : blue, $\mathrm{H}$ : white) leading to positively charged coordination complexes at ammono-neutral conditions ( $\mathrm{pH}=14$ at $300 \mathrm{~K}$ ). (b) Trivalent metal ion (yellow) solvation of in liquid ammonia ( $\mathrm{N}$ : blue, $\mathrm{H}$ : white) at ammono-neutral conditions ( $\mathrm{pH}=14$ at $300 \mathrm{~K}$ ). We find negatively charged coordination complexes for gallium ions, whilst neutral complexes are preferred for aluminum ion solvation. Amide ions are highlighted as spheres, whilst coordinating ammonia molecules are shown as sticks. 
Table 1 Monovalent metal ion solvation in liquid ammonia at $300 \mathrm{~K}$ Mimicking an autoclave scenario, the density is fixed to its average value at $240 \mathrm{~K}$ and $1 \mathrm{~atm}$. At these conditions the autoprotolysis of ammonia is related to a $\mathrm{pK}$ of 28 and $\Delta G=+177 \mathrm{~kJ} \mathrm{~mol}^{-1}$. 18 The free energy $G$ is set to zero for the complex species with lowest formation energy and $\Delta G$ refers to deviations from this reference point by (multiple) deprotonation reactions and subsequent relaxation in solution. For both $\mathrm{Na}^{+}$and $\mathrm{K}^{+}$we find $\mathrm{M}\left(\mathrm{NH}_{3}\right)_{y}{ }^{+}$complexes involving only ammonia coordination are favored over a wide $\mathrm{pH}$ range (columns highlighted by bold letters)

\begin{tabular}{|c|c|c|c|c|c|}
\hline $\begin{array}{l}\mathrm{M}^{\mathrm{I}}\left(\mathrm{NH}_{2}\right)_{x^{-}} \\
\left(\mathrm{NH}_{3}\right)_{y}{ }^{1-x}\end{array}$ & $x=0$ & $x=1$ & $x=2$ & $x=3$ & $x=4$ \\
\hline $\mathbf{M}=\mathbf{N a}$ & $y=6$ & $y=4$ & $y=2$ & - & - \\
\hline$d\left(\mathbf{M}-\mathrm{NH}_{2}\right)$ & - & $1 \times 2.3 \AA$ & $2 \times 2.25 \AA$ & & \\
\hline$d\left(\mathrm{M}-\mathrm{NH}_{3}\right)$ & $6 \times 2.35 \AA$ & $4 \times 2.3 \AA$ & $2 \times 2.55 \AA$ & & \\
\hline $\begin{array}{l}\Delta G-\Delta \Delta G / \\
\mathrm{kJ} \mathrm{mol}^{-1}\end{array}$ & $\boldsymbol{G}=\mathbf{0}$ & +120 & +289 & & \\
\hline $\mathrm{p} K_{\mathrm{a}}$ & 21 & 25 & - & & \\
\hline $\mathbf{M}=\mathbf{K}$ & $y=6$ & $y=6$ & $y=3$ & - & - \\
\hline$d\left(\mathbf{M}-\mathrm{NH}_{2}\right)$ & - & $1 \times 2.7 \AA$ & $2 \times 2.6 \AA$ & & \\
\hline$d\left(\mathbf{M}-\mathrm{NH}_{3}\right)$ & $6 \times 2.8 \AA$ & $6 \times 2.8 \AA$ & $3 \times 2.8 \AA$ & & \\
\hline $\begin{array}{l}\Delta G-\Delta \Delta G / \\
\mathrm{kJ} \mathrm{mol}^{-1}\end{array}$ & $\boldsymbol{G}=\mathbf{0}$ & +201 & +343 & & \\
\hline $\mathrm{p} K_{\mathrm{a}}$ & 35 & 36 & - & & \\
\hline
\end{tabular}

basic conditions are implemented. The estimated $\mathrm{p} K$ values of the $\mathrm{Na}\left(\mathrm{NH}_{3}\right)_{6}{ }^{+}$and $\mathrm{K}\left(\mathrm{NH}_{3}\right)_{6}{ }^{+}$are 21 and 35, respectively. The association of dispersed $\mathrm{NH}_{2}{ }^{-}$ions to the monovalent ions in liquid ammonia was found to be favored by $57 \mathrm{~kJ} \mathrm{~mol}^{-1} \mathrm{for}^{+}$, and disfavored by $24 \mathrm{~kJ} \mathrm{~mol}^{-1}$ for $\mathrm{K}^{+}$, respectively. This implies marginal reduction of the $\mathrm{p} K$ as compared to the bulk liquid $(28$ at $300 \mathrm{~K}$ ) upon introducing $\mathrm{Na}^{+}$ions, whilst $\mathrm{K}^{+}$ions do not assist the auto-protolysis at all.

In a similar fashion, the divalent ions $\mathrm{Mg}^{2+}$ and $\mathrm{Ca}^{2+}$ are also found as $\mathrm{M}\left(\mathrm{NH}_{3}\right)_{y}{ }^{2+}$ complexes (with $y=6$ and 8 for $\mathrm{M}=\mathrm{Mg}$ and $\mathrm{Ca}$, respectively) showing weak support for ammonia deprotonation. According to our 'local $\mathrm{p} K$ ' estimates, ammonia

Table 2 Analogous to Table 1, but for divalent metal ion solvation in liquid ammonia. $\mathrm{M}\left(\mathrm{NH}_{3}\right)_{y}{ }^{2+}$ complexes involving only ammonia coordination are favored over a wide $\mathrm{pH}$ range (columns highlighted by bold letters). At extremely basic conditions, two-fold deprotonation directly leads to complexes comprising two $(x=2)$ amide ions

\begin{tabular}{|c|c|c|c|c|c|}
\hline $\begin{array}{l}\mathrm{M}^{\mathrm{II}}\left(\mathrm{NH}_{2}\right)_{x^{-}} \\
\left(\mathrm{NH}_{3}\right)_{y}{ }^{2-x}\end{array}$ & $x=0$ & $x=1$ & $x=2$ & $x=3$ & $x=4$ \\
\hline $\mathbf{M}=\mathbf{M g}$ & $y=6$ & $y=5$ & $y=2$ & - & - \\
\hline$d\left(\mathrm{M}-\mathrm{NH}_{2}\right)$ & - & $1 \times 2.2 \AA$ & $2 \times 2.1 \AA$ & & \\
\hline$d\left(\mathrm{M}-\mathrm{NH}_{3}\right)$ & $6 \times 2.2 \AA$ & $5 \times 2.2 \AA$ & $2 \times 2.3 \AA$ & & \\
\hline $\begin{array}{l}\Delta G-\Delta \Delta G / \\
\mathrm{kJ} \mathrm{mol}^{-1}\end{array}$ & $\boldsymbol{G}=\mathbf{0}$ & +258 & +337 & & \\
\hline $\mathrm{p} K_{\mathrm{a}}$ & 29 & Unstable & - & & \\
\hline $\mathbf{M}=\mathbf{C a}$ & $y=8$ & $y=6$ & $y=3$ & - & - \\
\hline$d\left(\mathrm{M}-\mathrm{NH}_{2}\right)$ & - & $1 \times 2.7 \AA$ & $2 \times 2.6 \AA$ & & \\
\hline$d\left(\mathrm{M}-\mathrm{NH}_{3}\right)$ & $8 \times 2.7 \AA$ & $6 \times 2.8 \AA$ & $3 \times 2.8 \AA$ & & \\
\hline $\begin{array}{l}\Delta G-\Delta \Delta G / \\
\mathrm{kJ} \mathrm{mol}\end{array}$ & $\boldsymbol{G}=\mathbf{0}$ & +158 & +247 & & \\
\hline $\mathrm{p} K_{\mathrm{a}}$ & 21 & Unstable & - & & \\
\hline
\end{tabular}

Table 3 Analogous to Table 1, but for trivalent metal ion solvation in liquid ammonia. For both $\mathrm{Al}^{3+}$ and $\mathrm{Ga}^{3+}$ ion species, positively charged complexes are inaccessible to ammonia solutions (strongly negative $\mathrm{pK}$ as $\mathrm{NH}_{3}$ deprotonation is exothermic). While gallium ions are found as negatively charged $\mathrm{M}\left(\mathrm{NH}_{2}\right)_{4}\left(\mathrm{NH}_{3}\right)_{y}{ }^{-}$complexes for a wide $\mathrm{pH}$ range, neutral $\mathrm{Al}\left(\mathrm{NH}_{2}\right)_{3}\left(\mathrm{NH}_{3}\right)_{2}{ }^{0}$ complexes are observed for aluminum unless (mildly) ammono-basic conditions are imposed. Columns highlighted by bold letters indicate the preferred complexes at ammono-neutral conditions $(\mathrm{pH}=14$ at $300 \mathrm{~K})$

\begin{tabular}{|c|c|c|c|c|c|}
\hline $\mathrm{M}^{\mathrm{III}}\left(\mathrm{NH}_{2}\right)_{x}\left(\mathrm{NH}_{3}\right)_{y}{ }^{3-x}$ & $x=0$ & $x=1$ & $x=2$ & $x=3$ & $x=4$ \\
\hline $\mathbf{M}=\mathbf{A} \mathbf{l}$ & - & - & $y=8$ & $y=2$ & $y=2$ \\
\hline$d\left(\mathbf{M}-\mathrm{NH}_{2}\right)$ & & & $2 \times 2.8 \AA$ & $2 \times 1.7 \AA$ & $2 \times 1.7 \AA$ \\
\hline$d\left(\mathbf{M}-\mathrm{NH}_{3}\right)$ & & & $8 \times 2.9 \AA$ & $4 \times 2.3 \AA$ & $4 \times 2.3 \AA$ \\
\hline$\Delta G-\Delta \Delta G / \mathrm{kJ} \mathrm{mol}^{-1}$ & & & -282 & $\boldsymbol{G}=\mathbf{0}$ & +89 \\
\hline $\mathrm{p} K_{\mathrm{a}}$ & & & -49 & 15.5 & - \\
\hline $\mathbf{M}=\mathbf{G a}$ & - & - & $y=4$ & $y=2$ & $y=0$ \\
\hline$d\left(\mathbf{M}-\mathrm{NH}_{2}\right)$ & & & $2 \times 1.7 \AA$ & $3 \times 1.8 \AA$ & $4 \times 1.7 \AA$ \\
\hline$d\left(\mathbf{M}-\mathrm{NH}_{3}\right)$ & & & $4 \times 2.3 \AA$ & $2 \times 2.4 \AA$ & - \\
\hline$\Delta G-\Delta \Delta G / \mathrm{kJ} \mathrm{mol}^{-1}$ & & & -361 & $G=0$ & +7 \\
\hline $\mathrm{p} K_{\mathrm{a}}$ & & & -63 & 1.2 & - \\
\hline
\end{tabular}

molecules next to $\mathrm{Mg}^{2+}$ ions are slightly less likely to undergo auto-protolysis compared to the bulk liquid. On the other hand, $\mathrm{Ca}^{2+}$ ions assist amide formation similarly weak as $\mathrm{Na}^{+}$, but imposing two-fold complex deprotonation and relaxation (experienced as dissociation of $3 \mathrm{NH}_{3}$ molecules) was found to lead to the neutral $\left[\mathrm{Ca}\left(\mathrm{NH}_{2}\right)_{2}\left(\mathrm{NH}_{3}\right)_{3}\right]$ species.

For the trivalent metal ions explored, we however find a strikingly different trend. The $\mathrm{Ga}^{3+}$ ion species supports $\mathrm{NH}_{2}{ }^{-}$ association rather drastically, actually overcompensating the free energy change required for ammonia auto-protolysis. As illustrated in Fig. $2 \mathrm{~b}$, the predominant solvated species is given by $\left[\mathrm{Ga}\left(\mathrm{NH}_{2}\right)_{4}\right]^{-}$- hence negatively charged, tetrahedral amide complexes. This was recently suggested from the experiments of Niewa and coworkers. ${ }^{17}$ Indeed, our 'local $\mathrm{p} K$ ' estimate implies that rather drastic ammono-acidic conditions are required to obtain the charge neutral $\mathrm{Ga}\left(\mathrm{NH}_{2}\right)_{3}\left(\mathrm{NH}_{3}\right)_{2}{ }^{0}$ complex. Gallium complexes with less than 3 amide ions in the coordination shell could not be observed as stable species coexisting with dispersed $\mathrm{NH}_{2}{ }^{-}$in solution, thus further underlining the extreme tendency to amide formation next to the gallium ion.

$\mathrm{The} \mathrm{Al}^{3+}$ ions also behave ammono-acidic, but comparably weaker than $\mathrm{Ga}^{3+}$. At ammono-neutral conditions the uncharged $\mathrm{Al}\left(\mathrm{NH}_{2}\right)_{3}\left(\mathrm{NH}_{3}\right)_{2}{ }^{0}$ complex is most preferred. Therein the $3 \mathrm{NH}_{2}{ }^{-}$ions form a triangle, whilst the $2 \mathrm{NH}_{3}$ molecules constitute the top/bottom of a trigonal bi-pyramid. This unusual 5-fold coordination however reflects a $\mathrm{p} K$ of 15.5 which is near the $\mathrm{pH}$ of ammono-neutral solutions ( 14 at $300 \mathrm{~K}$ ). Thus, already mildly basic conditions lead to the formation of negatively charged $\mathrm{Al}\left(\mathrm{NH}_{2}\right)_{4}\left(\mathrm{NH}_{3}\right)_{2}{ }^{-}$complexes. For direct comparison, we plotted the $\mathrm{p} K$ of the bulk liquid and ammonia within the uncharged $\mathrm{M}\left(\mathrm{NH}_{2}\right)_{3}\left(\mathrm{NH}_{3}\right)_{2}{ }^{0}(\mathrm{M}=\mathrm{Al}, \mathrm{Ga})$ complexes as functions of temperature in Fig. 3.

Apart from the experimental and simulation data available for metal ion solvation in ammonia, at least some degree of comparison may be given by the different types of $\left[\mathrm{M}\left(\mathrm{NH}_{3}\right)_{x}\right]^{q}$ complexes in crystalline compounds. For example, 8-fold 


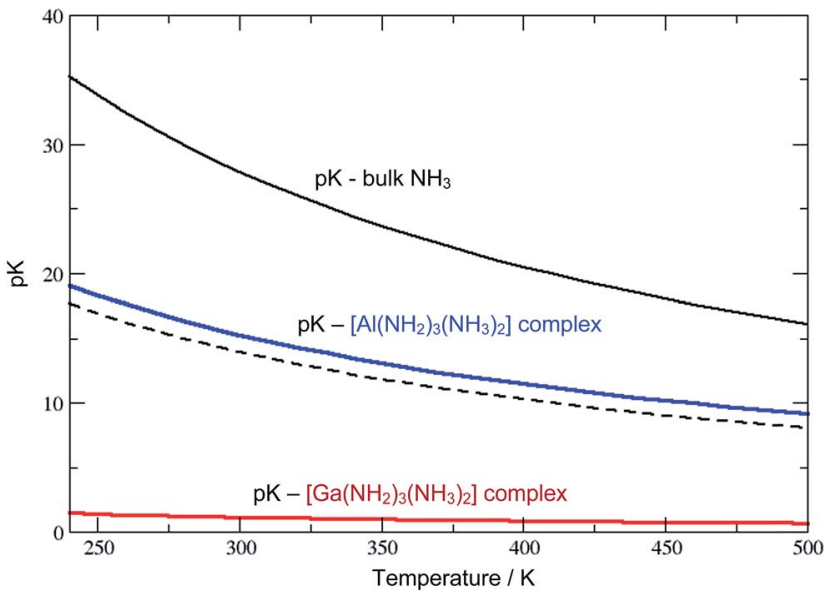

Fig. 3 Calculated values of $p K$ in liquid ammonia as functions of temperature (volume fixed to that at $240 \mathrm{~K}$ to mimic an autoclave scenario). The $\mathrm{p} K \mathrm{~s}$ (solid curves) of $\mathrm{NH}_{3}$ autoprotolysis for the bulk liquid are compared to $\mathrm{Al}\left(\mathrm{NH}_{2}\right)_{3}\left(\mathrm{NH}_{3}\right)_{2}$ and $\mathrm{Ga}\left(\mathrm{NH}_{2}\right)_{3}\left(\mathrm{NH}_{3}\right)_{2}$ complexes, as shown in black, blue and red, respectively. The dashed curve indicates ammono-neutral $\mathrm{pH}$, that is $-\log _{10}\left[\mathrm{NH}_{4}^{+}\right]$for the pure liquid as a function of temperature.

coordinated $\left[\mathrm{Ca}\left(\mathrm{NH}_{3}\right)_{8}\right]^{2+}$ complexes were observed in iodine and bromide salts, however not exhibiting a squareantiprismatic coordination. Moreover, the iodide compound showed transformation to $\left[\mathrm{Ca}\left(\mathrm{NH}_{3}\right)_{6}\right] \mathrm{I}_{2}$ upon heating. ${ }^{18}$ We feel that the gap between complexes embedded in crystal structures and those dispersed in liquid solution is too large to provide robust knowledge. In analogy to our recent study on $\mathrm{ZnO}$ precipitation from $\mathrm{Zn}^{2+} / 2 \mathrm{OH}^{-}$solution, yet ongoing efforts will therefore address the association of larger numbers of metal and amide ions to elaborate nucleation mechanisms including de-protonation and re-organization as functions of aggregate size. ${ }^{19,20}$

\section{Conclusion}

The 'local $\mathrm{p} K$ ' concept allows the inexpensive assessment of the protonation state of metal ion complexes in protic solution. Based on an earlier quantum/molecular mechanics simulation study of the auto-protolysis in liquid ammonia, we now outlined the calculation of $\Delta \mathrm{pK}$ correction terms. For both, $\mathrm{NH}_{3}$ autoprotolysis in the bulk liquid and when assisted by a metal ion complex, the excess $\mathrm{H}^{+}$is dispersed in the ammonia solution. The underlying $\Delta \Delta G$ solvation free energy is therefore given by the metal-ammonia versus metal-amide interactions, only. As these are dominated by electrostatics and van-der-Waals forces, we suggest the differences in the average potential energy as reasonable approximates to $\Delta \Delta G$. Using this simulation approach, a number of ionic species and different protonation states may be screened very effectively by means of molecular mechanics simulations. Our results demonstrate the role of both, metal ion charge and ion size in promoting different coordination clusters as functions of $\mathrm{pH}$.

\section{Conflicts of interest}

There are no conflicts to declare.

\section{References}

1 The Chemical Physics of Solvation, ed. R. R. Dogonadze, Elsevier, Amsterdam, 1985.

2 R. Bunsen, Ann. Phys., 1839, 46, 97-103.

3 K. Byrappa and M. Yoshimura, Handbook of Hydrothermal Technology: a Technology for Crystal Growth and Materials processing, Noyes Publications/William Andrew Publishing, LLC, Park Ridge, NY, USA, 2001.

4 T. M. M. Richter and R. Niewa, Inorganics, 2014, 2, 29-78.

5 H. Cao, J. Guo, F. Chang, C. Pistidda, W. Zhou, X. Zhang, A. Santoru, H. Wu, N. Schell, R. Niewa, P. Chen, T. Klassen and M. Dornheim, Chem.-Eur. J., 2017, 23, 9766-9771.

6 R. Dwilinski, A. Wysmolek, J. Baranowski, M. Kaminska, R. Doradzinski and H. Jacobs, Acta Phys. Pol., A, 1995, 88, 833-836.

7 Y. C. Lan, X. L. Chen, Y. G. Gao, Y. P. Yu, L. Xu and J. K. Liang, J. Cryst. Growth, 1999, 207, 247-250.

8 D. Zahn, Chem. Phys. Lett., 2017, 682, 55-59.

9 P. Li, L. F. Song and K. M. Merz, J. Chem. Theory Comput., 2015, 11, 1645-1657.

10 P. Li, B. P. Roberts, D. K. Chakravorty and K. M. Merz, J. Chem. Theory Comput., 2013, 9, 2733-2748.

11 P. Li, L. F. Song and K. M. Merz, J. Phys. Chem. B, 2015, 119, 883-895.

12 P. Zapol, R. Pandey and J. D. Gale, J. Phys.: Condens. Matter, 1997, 9, 9517-9525.

13 http://www.scd.stfc.ac.uk/SCD/44516.aspx.

14 J. C. Wasse, S. Hayama, S. Masmanidis, S. L. Stebbings and N. T. Skipper, J. Chem. Phys., 2003, 118, 7486-7494.

15 J. C. Wasse, S. Hayama and N. T. Skipper, J. Phys. Chem. B, 2003, 107, 14452-14456.

16 S. Hannongbua, M. Kiselev and K. Heinzinger, Condens. Matter Phys., 2000, 3, 381-392.

17 J. Hertrampf, E. Schlücker, D. Gudat and R. Niewa, Cryst. Growth Des., 2017, 17, 4855-4863.

18 P. Woidy, A. J. Karttunen, T. G. Müller and F. Kraus, Z. Naturforsch., B: J. Chem. Sci., 2014, 69, 1141-1148.

19 A. Kawska, P. Duchstein, O. Hochrein and D. Zahn, Nano Lett., 2008, 8, 2336-2340.

20 J. Anwar and D. Zahn, Angew. Chem., Int. Ed., 2011, 50, 19962013. 